For patients who seem to have rheumatoid arthritis at presentation it is important to identify those who will not progress - that is, not develop erosions. Such patients can be treated symptomatically or given a short course of steroids. This study indicates that patients with fewer than two risk factors fall into this category. The second important group to distinguish are those who will have persistent and erosive disease, for whom early use of a slow acting antirheumatic drug would be appropriate. Patients possessing two or three risk factors are, from the evidence of this study, likely to have this outcome. An additional goal is to identify the small group of patients with a rapidly progressive course of the disease. Fortunately, with current treatment this is a relatively rare outcome and consequently the small number of patients is too few to be identified in a study of this size. The ability to identify such individuals at presentation, however, will become more relevant as specific immunomodulatory treatment becomes available. Large multicentre studies ${ }^{13}$ have been set up to produce the power to identify the predictive factors for such patients and will allow the testing of the results of this preliminary study with a much larger number of patients.

We thank the Arthritis and Rheumatism Council for financial support and the epidemiology research unit, Manchester, for statistical advice.
Harris ED. The clinical features of rheumatoid arthritis. In: Kelly ww Harris ED, Ruddy MD, Sledge CB, eds. Textbook of rheumatology. 3rd ed. Philadelphia: Saunders, 198

2 Van der Heijde DMFM, van Riel PLCM, van Rijswijk MH, van de Putte LBA. Influence of prognostic features on the final outcome in RA. A review of the literature. Semin Arthritis Rheum 1988;17:284-92.

3 Gregersen PK, Shen M, Song QL, Merryman P, Degar S, Seki T, et al. Molecular diversity of HLA-DR4 haplotypes. Proc Natl Acad Sci USA 1986;83:2642.

4 Winchester RJ, Gregersen PK. The molecular basis of susceptibility to rheumatoid arthritis: the conformation equivalence hypothesis. Springer Semin Immunopathol 1988:10:119-39.

5 Wordsworth BP, Lanchbury JSS, Sakkas LI, Welsh KI, Bell JI. HLA-DR subtype frequencies in rheumatoid arthritis indicate that DRBl is the major subtype frequencies in rheumatold arthritis indicate that DRBl is the major
susceptibility locus within the HLA class II region. Proc Natl Acad Sci USA 1989;86:10049.

6 Emery P, Panayi GS, Huston G, Welsh KI, Waring R, Mitchell SC. D-Penicillamine-induced toxicity in rheumatoid arthritis: the role D-Penicillamine-induced toxicity in rheumatoid arthritis: the
sulphoxidation status and HLA-DR3. I Rheumatol 1984;11:626-32.

7 Emery P, Bradley H, Gough A, Arthur V, Jubb R, Waring RH. Increased prevalence of poor sulphoxidation in patients with rheumatoid arthriti Ann Rheum Dis 1992;51:318-20.

8 Mitchell SC, Waring RH, Haley CS, Idle JR, Smith RL. Genetic aspects of the polymodally distributed sulphoxidation of S-carboxymethyl-L-cysteine in man. Br f Clin Pharm 1984;18:507-21.

9 Gardiner M, Altman DG. Statistics with confidence-confidence intervals and statistical guideline. London: BMJ, 1989.

10 Wilkins RF, Nepom GT, Marks J, Nettles JW, Nepom BS. Association of HLA Dwl6 with RA in Yakima indians: further evidence for the shared epitope hypothesis. Arthritis Rheum 1991;34:43.

11 Wordsworth BP, Stedeford J, Rosenberg WMC, Bell JI. Limited heterogeneity of the class II contribution to susceptibility to rheumatoid arthritis is suggested by positive associations with HLA-DR4 and DRw10. Br f Rheum suggested by $1990: 30: 178$.

12 Young A, Cox N, Dixie J, James D, Gough A, Gallivan S, et al. Early rheumatoid arthritis study (ERAS). Report of first 506 patients. Arthritis Rheum 1991;34:9 S48;93.

(Accepted 6 October 1992)
Department of Surgery, Charing Cross Hospital, London W6 8RF Christine J Moffatt, clinical nurse specialist

Peter J Franks, lecturer Margaret Oldroyd, research nurse

Roger M Greenhalgh, professor of surgery

Department of Social Policy, Royal Holloway and Bedford New College, University of London, Surrey TW20 0EX

Nick Bosanquet, professor of health policy

Family and Community Services Unit, Riverside District Health Authority, West London Hospital, London W6 7DQ

Pearl Brown, manager,

primary services

Department of Surgery, University Hospital of South Manchester, West Didsbury, Manchester M20 8LR

Charles N McCollum,

professor of surgery

Correspondence to: Mrs Moffatt.

\title{
Community clinics for leg ulcers and impact on healing
}

\author{
Christine J Moffatt, Peter J Franks, Margaret Oldroyd, Nick Bosanquet, Pearl Brown, \\ Roger M Greenhalgh, Charles N McCollum
}

\section{Abstract}

Objective-To evaluate the effectiveness of community clinics for leg ulcers.

Design-All patients with leg ulceration were invited to community clinics that offered treatment developed in a hospital research clinic. Patients without serious arterial disease (Doppler ankle/ brachial index $>0.8$ ) were treated with a high compression bandage of four layers.

Setting-Six community clinics held in health centres in Riverside District Health Authority supported by the Charing Cross vascular surgical service.

Patients-All patients referred to the community services with leg ulceration, irrespective of cause and duration of ulceration.

Main outcome measures-Time to complete healing by the life table method.

Results-550 ulcerated legs were seen in 475 patients of mean (SD) age 73.8 (11.9) years. There were 477 venous ulcers of median size $4.2 \mathrm{~cm}^{2}$ (range $0 \cdot 1-117 \mathrm{~cm}^{2}$ ), 128 being larger than $10 \mathrm{~cm}^{2}$. These ulcers had been present for a median of three months (range one week to 63 years) with 150 present for over one year. Four layer bandaging in the community clinics achieved complete healing in 318 $(69 \%)$ venous ulcers by 12 weeks and $375(83 \%)$ by 24 weeks. There were 56 patients with an ankle/brachial arterial pressure index $<0.8$, indicating arterial disease. The 50 patients with pressure index $<0.8>0.5$ were treated with reduced compression, and $24(56 \%)$ healed by 12 weeks and $31(75 \%)$ by 24 weeks. The figures for overall healing for all leg ulcers were $351 / 550(67 \%)$ at 12 weeks and $417 / 550$ $(81 \%)$ at 24 weeks, compared with only $11 / 51(22 \%)$ at 12 weeks before the community clinics were set up.

Conclusions-Community clinics for venous ulcers offer an effective means of achieving healing in most patients with leg ulcers.

\section{Introduction}

The treatment of leg ulceration has been delegated predominantly to district nurses, with poor healing despite their hard work. Nationally, district nurses spend up to half of their time treating leg ulcers. ' Half the patients are seen more than twice weekly and over a fifth treated daily. Clinical research has generally been of poor quality and the resulting service is uncoordinated and largely ineffective.

Until recently management of ulcers was rarely based on sound scientific principles; instead marketing pressures have influenced the choice of dressings, irrespective of efficacy. ${ }^{23}$ Diagnosis and investigation of these patients have been little better, with few objective attempts to determine the cause of ulceration in each patient.

Various new approaches to the clinical management of these ulcers were developed in a research ulcer clinic in the vascular surgical service at Charing Cross Hospital. These included a four layer compression bandage, which achieved a healing rate of $74 \%$ at 12 weeks in outpatients with venous ulcers and the introduction of pinch skin grafting and venous assessment. ${ }^{+6}$ This service was rapidly overcome by referrals so that only a small proportion of patients could be seen, with most remaining under the care of district nurses.

To determine whether a service based in the community could achieve comparable rates of healing, a network of community clinics was established throughout Riverside District Health Authority, providing easy access for all patients with leg ulcers to the new methods of assessment and treatment. These 
clinics were run by community nurses, trained and guided by nurse specialists in the vascular surgical service who also recorded both the clinical results and costs of the new service.

\section{Methods}

Baseline audit-To establish the scale of need district nurses from one health centre were asked to complete a diary of visits to all patients with leg ulceration over 18 weeks. The date of each visit was recorded for each patient together with the time when the ulcer healed.

Setting up community clinics-After distributing an information pack and a meeting at each health centre or general practice surgery, two district nurses were nominated to act as coordinating sisters responsible for the daily running and ordering for the clinic. The workload of the district nurses was reorganised. The transport of patients proved to be difficult but an ambulance adapted to transport wheelchairs was bought and a part time driver employed, enabling many disabled patients to attend the clinics. The two nurse specialists from the hospital attended each new clinic to train the relevant district nurses in the assessment of patients, bandaging techniques, and accurate recording of patient details. The clinic was considered to be part of the normal workload of these community nurses, who progressively took more responsibility for the running of their clinic.

\section{MANAGEMENT OF ULCERS}

Assessment-Peripheral arterial disease was assessed by measuring the ankle/brachial pressure index with a simple handheld Doppler probe (Huntleigh Technology). ${ }^{7}$ Other causes of ulceration, including carcinoma, diabetes, or rheumatoid vasculitis, were identified when possible and treatment or referral was offered. Leg ulcers affecting the lower calf and ankle region with ankle/brachial pressure indices of $>0.8$ and no evidence of skin cancer were described as venous ulcers.

Dressings and bandages were changed once each week and as previous research on a variety of dressing materials had failed to identify any product achieving greater rates of healing than simple non-adherent dressing (NA, Johnson and Johnson) this was used throughout this study. ${ }^{89}$ Compression was achieved by a high compression bandage system of four layers developed to apply $40 \mathrm{~mm} \mathrm{Hg}$ at the ankle graduated to under $20 \mathrm{~mm} \mathrm{Hg}$ just below the knee. ${ }^{4}$ The diameter of the ankle is important as the pressure beneath elastic bandages is greater for narrow ankles and least for wide ankles. Each four layer bandage may incorporate different bandages designed to achieve this compression sustained over at least one week, despite the wide range in ankle sizes (table I).

Measurement of ulcer size and recording results-At each weekly follow up visit the total area of ulceration on each leg was traced on to clear acetate paper, the area of which was then measured with computer planimetry. This and clinical records of each visit were entered on study forms.

Prevention of recurrence-All patients who achieved complete healing were fitted with elastic below knee compression stockings giving about $23 \mathrm{~mm} \mathrm{Hg}$ compression at the ankle (class II, Doumed, Medi UK Ltd) and followed up every three months. Only 12 patients who were unable to wear compression stockings required long term maintenance bandaging.

Patients with other types of ulcer-Patients with arterial disease and an ankle/brachial pressure index of $<0.5$ were immediately referred to a vascular surgeon. Those with pressure indices $>0.5<0.8$ were treated with a reduced pressure technique with a three layer bandage by removing the Elset (or Plastex) layer from the bandage regimen (table I). Any ulcer that appeared unusual, failed to granulate, or looked malignant was sampled for biopsy and patients with malignant changes referred for surgery.

VENOUS ASSESSMENT AND SURGERY

Patients judged adequately fit for simple venous surgery (under a local anaesthetic if necessary) were assessed in the vascular laboratory at the hospital by ambulatory venous pressures and duplex Doppler imaging of venous incompetence.

\section{DATA ANALYSIS}

The time to complete ulcer healing was analysed by life tables. Comparison of healing rates was made with the log rank method with relative risks and 95\% confidence intervals calculated from the hazard rates. The comparison of factors related to the ulcer such as cause, pressure index, size, and duration of ulceration was made for individual legs. For patient factors such as general mobility and place of treatment comparison was made by using the larger ulcer.

\section{Results}

The first community ulcer clinic was established in February 1989, and by March 1991, 475 patients had been treated (table II). The mean (SD) age was 73.8 (11.9) years; j22 patients were women. Of the total, 209 suffered from some limitation in mobility, with three bedbound and 32 chairbound. Overall, only 50 were considered too unfit to attend the clinic and.were visited at home.

Four patients had skin cancer confirmed by biopsy. The 471 remaining patients had a total of 550 ulcerated legs, of which 392 were unilateral and 79 bilateral. Of the 56 patients in whom the ankle/brachial arterial pressure index was $<0 \cdot 8$, indicating arterial disease, 15 were referred to the vascular service with indices $<0.5$. N Rheumatoid vasculitis was suspected in a further eight, $D$ and in seven ulceration of the foot and the clinical history suggested that diabetes was the main cause. In two patients the cause of ulceration was unknown with the remaining 477 ulcers thought to be caused by venous disease and described as venous ulcers. Over

TABLE II-Details of patients presenting to community clinics with leg ulceration

\begin{tabular}{|c|c|c|c|c|c|c|c|}
\hline & \multicolumn{6}{|c|}{ Name of clinic } & \multirow[b]{2}{*}{ Total } \\
\hline & Worlds End & Milson Road & St Dunstans & White City & $\begin{array}{l}\text { Bessborough } \\
\text { Street }\end{array}$ & Parsons Green & \\
\hline Date of starting & 3 February 1989 & 4 July 1989 & 7 November 1989 & 6 November 1989 & 21 May 1990 & 26 September 1990 & \\
\hline No of patients & 122 & 103 & 83 & 74 & 52 & 41 & 475 \\
\hline No of women & $88(72 \%)$ & $68(66 \%)$ & $57(69 \%)$. & $53(72 \%)$ & $31(60 \%)$ & $26(63 \%)$ & $323(68 \%)$ \\
\hline Mean (SD) age (years) & $74 \cdot 7(12 \cdot 5)$ & $73 \cdot 3(12 \cdot 2)$ & $72 \cdot 3(11 \cdot 5)$ & $72 \cdot 1(12 \cdot 8)$ & $75 \cdot 2(11 \cdot 9)$ & $76 \cdot 8(7 \cdot 6)$ & $73 \cdot 8(11 \cdot 9)$ \\
\hline \multicolumn{8}{|l|}{ Mobility: } \\
\hline Bed or chairbound & $10(8 \%)$ & $10(10 \%)$ & $5(6 \%)$ & $3(4 \%)$ & $5(10 \%)$ & $2(5 \%)$ & $35(7 \cdot 4 \%)$ \\
\hline Walk with aid & $50(42 \%)$ & $39(38 \%)$ & $21(25 \%)$ & $33(45 \%)$ & $17(33 \%)$ & $14(34 \%)$ & $174(36.7 \%)$ \\
\hline Walk freely & $61(50 \%)$ & $54(52 \%)$ & $57(69 \%)$ & $38(51 \%)$ & $30(58 \%)$ & $25(61 \%)$ & $265(55.9 \%)$ \\
\hline \multicolumn{8}{|l|}{ Place of treatment: } \\
\hline Clinic & $107(88 \%)$ & $84(82 \%)$ & $75(90 \%)$ & $69(93 \%)$ & $49(94 \%)$ & $39(95 \%)$ & $423(89 \cdot 2 \%)$ \\
\hline Home & $14(12 \%)$ & $19(18 \%)$ & $8(10 \%)$ & $5(7 \%)$ & $3(6 \%)$ & $2(5 \%)$ & $51(10.8 \%)$ \\
\hline
\end{tabular}


the two years of the study 90 patients attended for a venous assessment. Of these, only five patients met the predetermined criteria and wished to proceed with surgery to correct their underlying disease.

During the control period of 18 weeks 51 patients with ulcers were treated by the district nurses attached to one of the health centres. The results from this study showed that only 11 were completely healed after 12 weeks of treatment. These patients were the first to be seen in the community clinics. Over the first three months of the clinics over half (72) of the 134 patients seen were completely healed.

The 477 venous ulcers had a median size of $4.2 \mathrm{~cm}^{2}$ (range $0 \cdot 1-117 \mathrm{~cm}^{2}$ ) with 128 being larger than $10 \mathrm{~cm}^{2}$. They had been present for a median duration of three months (range one week to 63 years) with 150 being present for over one year. When we analysed the data by life tables $69 \%$ (318/477) venous ulcers had completely healed by 12 weeks and $83 \%$ (375/477) had healed by 24 weeks. In the 50 patients with mild arterial disease (ankle/brachial arterial pressure index $<0.8>0.5)$ the healing rate was still $56 \%(24 / 50)$ at 12 weeks and $75 \%(31 / 50)$ at 24 weeks (relative risk $1 \cdot 26,95 \%$ confidence interval $0 \cdot 89$ to $1 \cdot 79 ; p=0 \cdot 164)$. The overall healing rate for all leg ulcers was $67 \%$
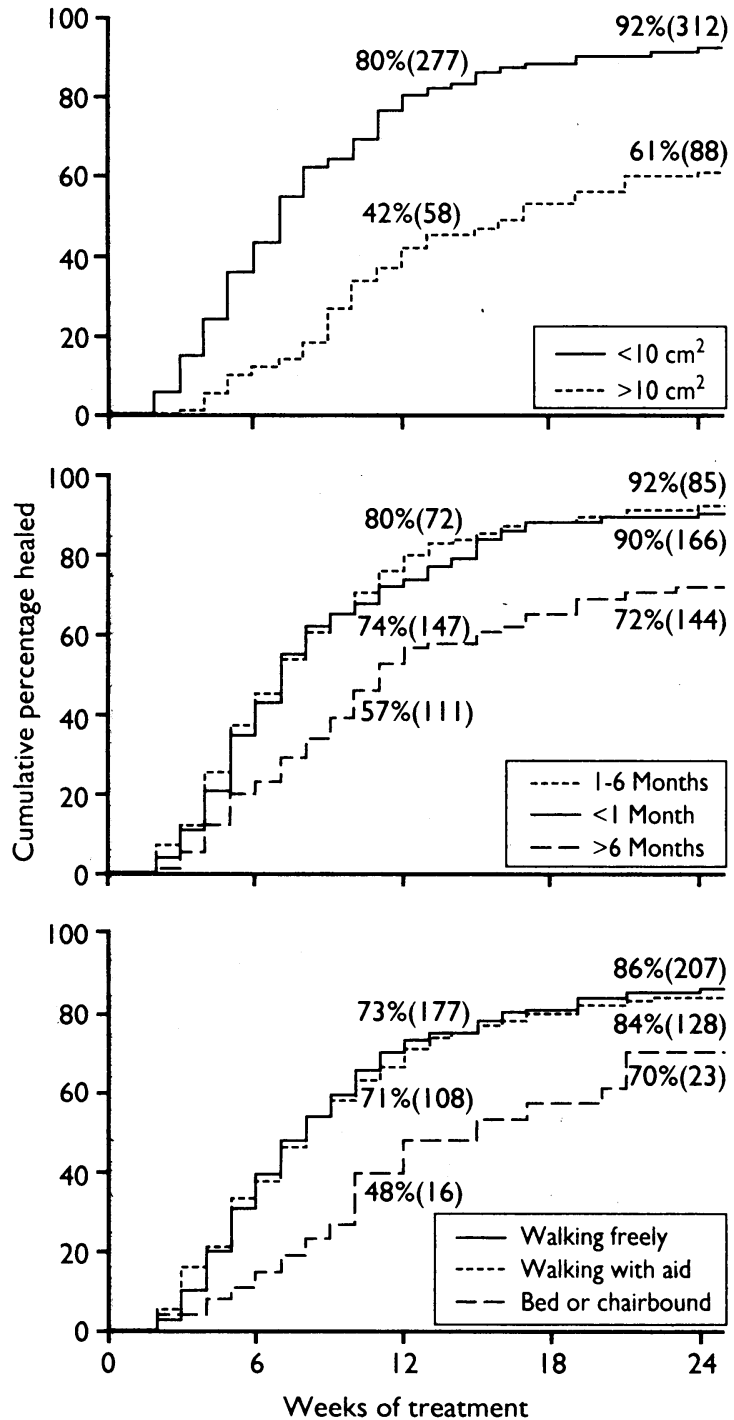

FIG 1-Cumulative rates of healing of limbs with venous ulceration: (a) comparing healing in ulcers $<10 \mathrm{~cm}^{2}$ (336) and $\geqslant 10 \mathrm{~cm}^{2}(128)$ risk was 2.47 ( $95 \%$ confidence interval 1.95 to $3 \cdot 14, p<0.001)$; (b) comparing ulcers present for $<1$ month (178) with 1-6 months (93) risk was $0.95(0.73$ to $1.24, p=0.702)$, but for ulcers present $>6$ months (186) risk of healing was 1.91 (1.45 to 2.52, $p<0.001$ ); (c) comparing patients who walked freely (235) and those who required walking aid (148) risk of healing was $1.04(0.84$ to $1.30, p=0.703)$, and compared with those who were bed or chairbound (28) risk was $1 \cdot 89(1 \cdot 17$ to $3.06, p=0.004)$

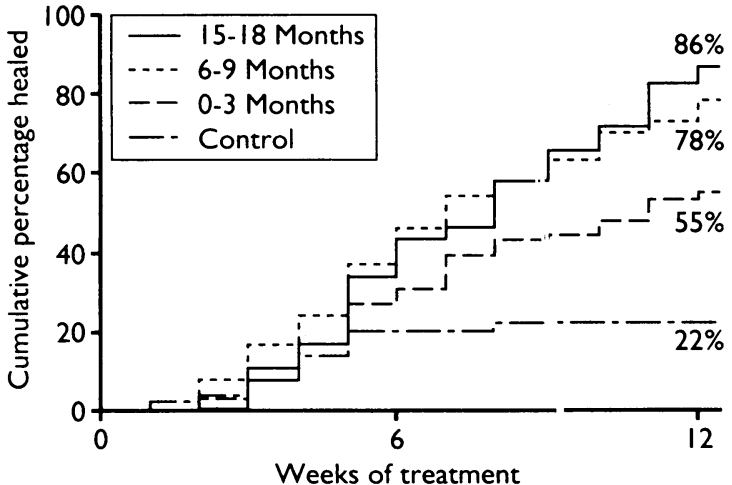

FIG 2-Healing rates of all patients with leg ulceration by time of referral after start of each clinic and compared with cont: $o l$ study (to 12 weeks only)

(351/550) at 12 weeks improving to $81 \%(41 \% / 550)$ after 24 weeks of treatment. Of the 40 patients (with 48 legs affected) who failed to heal and were treatied for less than 24 weeks, 16 died, 11 refused treatment, five were treated elsewhere, five moved away, and there were three amputations. One amputation was for r heumatic disease, one for gangrene, and the other for gas gangrene. These patients were all include 1 in the analysis up to the time when they stopped attending the community ulcer clinics.

As expected venous ulcers greater than $10 \mathrm{~cm}^{2}$ healed more slowly than ulcers less than $10 \mathrm{~cm}^{2}$, at $42 \%$ (52) and $80 \%$ (259) respectively healed by 12 weeks (fig 1a). Patients with longlasting and chronic venous ulcers also healed slower with $57 \%$ (101) of the 186 venous ulcers present for longer than six rnonths healed within 12 weeks compared with $80 \%$ (l19) of the 178 ulcers present for between one to six nionths and $74 \%$ (67) of the 93 present for less than one inonth (fig 1b).

The 38 patients with venous ulcers treated at thome healed more slowly than the 373 who attenciled a community clinic, despite identical assessment and treatment, with healing rates at 12 weeks of $66 \%$ (20) and $72 \%$ (258) respectively $(1.61,1.10$ to $: 2.52$; $\mathrm{p}=0 \cdot 008$ ). This may relate to the reduced mobili ty in these patients as only 12 of the 28 bed or chairbciund patients healed by 12 weeks compared with $102(71 \%)$ of the 148 patients who could walk with an aid and $165(73 \%)$ of the 235 who could walk freely (fig 1c)

Healing rates improved with time after setting up each new clinic. Of the patients who presented in the first three months, $55 \%(72 / 134)$ healed by 12 week: of treatment compared with $78 \%(59 / 76)$ at six to nine months and $86 \%(28 / 38)$ of those who presented at 15-18 months. This occurred because patients we re referred earlier and the chronic, longstanding ulce rs were progressively healed (fig 2 ).

\section{Discussion}

These results clearly show that effective care of les: ulcers can be undertaken in special clinics within the community provided that adequate training, equipment, and elastic bandages are provided. Even large and chronic ulcers heal at a rate which compares favourably with the results from recently published trials in which just over $30 \%$ of all patients healed within 12 weeks of starting treatment. ${ }^{10}$

Most patients with ulcers were previously treated in the community by either district nurses, the patient, or the patient's relative. ${ }^{3}$ Our experience in setting up ulcer clinics for research confirmed what was already known by district nurses: that all patients with leg ulceration could not be treated in hospital.

Each clinic required a small initial budget for equipment such as the handheld Doppler probes. 
Three of the four bandages had to be ordered by the district supplies department as they could not be obtained on prescription. The cost of bandages for all six clinics for one year was about $£ 35-40000$. The family health services committee probably already pays a similar or larger amount for materials currently available and used on FP10 prescription but which are largely ineffective in achieving ulcer healing. Transfer of this budget to district supplies or the recognition of these bandages on drug tariff would seem to be the way forward.

About a tenth of the patients in this study had significant arterial disease shown by low ankle/ brachial pressure indices, so that compression bandaging was contraindicated and may have lead to pressure necrosis and amputation. ${ }^{311}$ It is therefore essential that the community staff are trained to assess patients for arterial disease so that the correct treatment is offered.

The main thrust of this study was the setting up of community ulcer clinics and assessing the results of this service. Despite the success of this service in treating ulcerated legs it must be acknowledged that reulceration is a major problem in these patients. Preliminary analysis of rates of recurrence in this study has shown that about a fifth of legs reulcerate within six months of healing and a third by one year, despite regular visits for compression hosiery. These results may be improved by using skin grafting techniques or venous surgery in more patients than was possible in this first attempt at a comprehensive community ulcer service.

This study has drawn together community and hospital staff around a single common problem Community nurses have observed real improvements in the care of their patients, which has given them additional job satisfaction. There is a clear need for a coordinated community based approach to this common and socially isolating condition, centred on a nurse specialising in venous ulcers.

The project was awarded the King Edward's Hospital Fund major grant award for 1988 for which we are grateful. We thank all members of the community service of Riverside District Health Authority for their cooperation and enthusiasm

1 Callam MJ, Ruckley CV, Harper DR, Dale JJ. Chronic ulceration of the leg: extent of the problem and provision of care. BMF 1985;290:1855-6.

2 Bale S. Community nurses' awareness of dressing materials. Care 1989;7:90-2. Cornwall JV, Dore CJ, Lewis JD. Leg ulcers: epidemiology and aetiology. 0 Brf Surg 1986;73:693-6.

4 Blair SD, Wright DDI, Backhouse CM, Riddle E, McCollum CN. Sustained. compression and healing of chronic venous ulcers. BMF 1988;297:1159-61.

5 Poskitt KR, James AH, Lloyd-Davies ERV, Walton J, McCollum CN. Pinch $\vec{\omega}$ skin grafting or porcine dermis in venous ulcers: a randomised clinical trial. BM7 1987;294:674-7.

6 Wright DDI, Meek A, McCollum CN, Greenhalgh RM. Functional tests for venous insufficiency. 7 Cardiovasc Surg 1987;28:97.

Yao JST, Hobbs JT, Inine WTT A arterial disease ffecting the lower extremities. Br f Surg 1969;56:676-9.

8 Backhouse C, Blair SD, Walton J, McCollum CN. A controlled trial of $\sigma$ occlusive dressings in the healing of chronic venous ulcers. Br $f$ Surg 1987;74:626-7.

9 Blair SD, Backhouse C, Wright DDI, Riddle E, McCollum CN. Do dressings influence the healing of chronic venous ulcers? Phlebology 1988;3:129-34.

10 Colgan M-P, Dormandy JA, Jones PW, Schraibman IG, Shanik DG, Young RAL. Oxpentifylline treatment of venous ulcers. BMF 1990;300:972-5.

11 Callum MJ, Ruckley CV, Dale JJ, Harper DR. Hazards of compression on treatment of the leg: an estimate from Scottish surgeons. BMF 1987;295: G 1382.

(Accepted 6 October 1992)

Serum antioxidant vitamins and risk of cataract

\author{
Paų Knekt, Markku Heliövaara, AiląRissanen, Arpo_Aromaa, Ritva-KaarinąAaran
}

Abstract

Objective-To investigate serum concentrations of $\alpha$ tocopherol, $\beta$ carotene, retinol, and selenium for their prediction of end stage cataract.

Design-A case-control study, nested within a cohort study, based on the linkage of records of subjects aged 40-83 from a health survey with those from the national Finnish hospital discharge register.

Subjects -47 patients admitted to ophthalmological wards for senile cataract over 15 years and two controls per patient individually matched for sex, age, and municipality.

Main outcome measure-Concentration of serum micronutrients, development of cataract according to whether operation was performed.

Results-Low serum concentrations of antioxidant vitamins predicted the development of senile cataract, the odds ratio between the lowest third and the two higher thirds of the distribution of serum concentrations of $\alpha$ tocopherol and $\beta$ carotene being $1.9(95 \%$ confidence interval 0.9 to $4 \cdot 1)$ and $1.7(0.8$ to 3.8), respectively. Patients with both $\alpha$ tocopherol and $\beta$ carotene concentrations in the lowest third had an odds ratio of $2.6(1.0$ to 6.8$)$ of cataract compared with subjects in the top two thirds. The associations were strengthened by adjustment for potential confounding factors such as occupation, smoking, blood pressure, serum cholesterol concentration, body mass index, and diabetes. No association was found between the serum concentrations of selenium, retinol, and retinol binding protein and the risk of cataract.
Conclusions-Low serum concentrations of the $\overrightarrow{\vec{\rho}}$ antioxidant vitamins $\alpha$ tocopherol and $\beta$ carotene are $\frac{\rho}{3}$ risk factors for end stage senile cataract. Controlled $\mathcal{}$ trials of the role of antioxidant vitamins in cataracto prevention are therefore warranted.

\section{Introduction}

Age related cataract is the common cumulative response to various damaging influences attacking the capsule, epithelium, and constituent fibres of the lens $\mathrm{O}$ of the eye.' The oxidation of lens proteins by free radicals is believed to play an important part in the $\tilde{N}$ multifactorial process leading to lens opacification. ${ }^{2} \mathrm{O}$ This process may be modified by micronutrients with an antioxidant capacity, such as $\alpha$ tocopherol, $\beta N$ carotene, and selenium. Some evidence from experimental $^{2}$ and cross sectional case-control studies ${ }^{3-6} \frac{\mathrm{O}}{2}$ supports this hypothesis, but it has not previously beene tested in a longitudinal study.

We examined the association between serum $\alpha \stackrel{\mathbb{\Phi}}{\rightarrow}$ tocopherol, $\beta$ carotene, and selenium concentrations 0 and the subsequent risk of end stage senile cataract over a median follow up of 15 years.

\section{Subjects and methods}

The mobile clinic unit of the Social Insurance Institution carried out multiphasic health examinations in 58440 Finns aged 15-99 years in various parts? of Finland during 1966-72. ${ }^{7}$ Serum concentrations of micronutrients were determined from a sample of 1419 people who initially served as a sex and age matched 